\title{
Delineation of a complexly dipping temperate glacier bed using short-pulse radar arrays
}

\author{
M. L. Moran, ${ }^{1}$ R. J. Greenfield,${ }^{2}$ S. A. Arcone, ${ }^{1}$ A. J. Delaney ${ }^{1}$ \\ ${ }^{1}$ Cold Regions Research and Engineering Laboratory, U.S. Army Corps of Engineers, 72 Lyme Road, Hanover, New Hampshire 03755-1290, U.S.A. \\ ${ }^{2}$ Department of Geosciences, The Pennsylvania State University, University Park, Pennsylvania 16802-7501, U.S.A.
}

\begin{abstract}
We have defined the complex bed topography for a section of a small temperate glacier using $50 \mathrm{MHz}$ monostatic short-pulse radar data and a synthetic-aperture array-processing method. The data were collected on a $100 \mathrm{~m}$ by $340 \mathrm{~m}$ array grid in the upper stem of Gulkana Glacier, central Alaska, U.S.A. The array processing was based on a modified three-dimensional (3-D) Kirchhoff migration integral and implemented with a synthetic-aperture approach that uses sequences of overlapping sub-arrays to generate depth images in vertical planes. Typical sub-array beam patterns are generally $<5^{\circ}$ at the $-6 \mathrm{~dB}$ level, giving a flashlight-like searching capability without distorting the wavelet shape. The bed topography was constructed using normal reflections picked from 3-D array depth images. In some instances reflections were imaged outside the data-coverage area. The bed surface dips steeply, both parallel and transverse to the direction of ice flow. The maximum observed depth is roughly $140 \mathrm{~m}$. The $3-\mathrm{D}$ method resolved bed dips up to $45^{\circ}$. In regions of steepest dip, it improved depth accuracy by $36 \%$ compared with raw data, and by $15 \%$ compared with standard two-dimensional (2-D) migration. Over $12 \mathrm{~dB}$ of signal-to-noise improvement and improved spatial resolution was achieved compared to raw data and 2-D migration. False bottom layering seen in the raw data and in 2$\mathrm{D}$ migrations is not observed in the 3-D array results. Furthermore, loss of bottom reflections is shown by the 3-D migration to be attributable to the dip and curvature of the reflector, and not scattering losses or signal clutter from englacial inclusions.
\end{abstract}

\section{INTRODUCTION}

The topography and nature of the materials near the bottom of temperate glaciers are of interest to studies of mass balance, surging, erosion and sediment transport. Direct methods, such as drilling, and traditional glacial remotesensing (geophysical) techniques are incapable of spatially mapping the character of temperate-glacier bottom structures. State-of-the-art geophysics data-acquisition and -processing techniques have the potential for delineating many of the basal ice characteristics of interest to glaciologists. In this paper we present three-dimensional (3-D) radar array-processing methods that can characterize the bottom of a temperate glacier with a much higher degree of accuracy than traditional two-dimensional (2-D) radar techniques.

High-resolution, short-pulse, ground-penetrating radar (GPR) surveys of temperate glaciers are usually interpreted for ice depth using either unprocessed single profiles or standard 2-D migration. For ice thicknesses of $<100 \mathrm{~m}$, GPR profiles are usually obtained with systems operating in a $30-$ $500 \mathrm{MHz}$ bandwidth. In this frequency range, temperate glaciers are inherently high-clutter radar environments with coherent but unwanted noise (Watts and England, 1976). In many cases, this clutter noise severely limits the effectiveness of radar surveys. The clutter is generated by diffractions from small englacial water and debris inclusions (Smith and Evans, 1972) and laterally propagating airwaves reflected from surface discontinuities (Clough, 1976; Arcone, 1984). When one uses short-pulse GPR antennas having low directivity (Arcone, 1995), these forms of clutter production are highly problematic and lead to difficulties in record-section interpretation. In cases where good signal penetration is achieved, despite clutter, interesting englacial and basal ice reflections and diffractions often suggest features relevant to the hydrological and dynamic characteristics of temperate ice sheets. These events have been interpreted as conduits or water bodies (Blindow and Thyssen, 1986; Arcone and others, 1995), thrust planes (Lønne and Lauritsen, 1996; Murray and others, 1997) and basal ice layers (Arcone and others, 1995; Murray and others, 1997). However, some of the prominent diffractions in these profiles suggest that out-of-plane scattering may have coincidentally placed these reflected signals in arrival-time proximity with the basal ice reflections. A shortduration wavelet with a tightly confined, high-gain radiation pattern would contain less signal clutter (Watts and England, 1976; Skolnik, 1962) and have good resolution capabilities.

Several approaches have been used to reduce radar clutter in temperate-glacier surveys. For example, electrically large antennas produce records with less clutter by achieving a high gain and narrow beamwidth. However, large antennas produce extended wavelets with many oscillations that compromise vertical resolution. As shown by Smith and Evans (1972) and Watts and England (1976), long-wavelength impulse radar at center frequencies of $2-8 \mathrm{MHz}$ can overcome scattering losses and bring out bottom reflections. Recent trends in temperate-glacier radar surveys indicate that this is currently the consensus approach for overcoming the clutter problem (Trabant and others, 1991; Harrison and others, 1994; Nolan and others, 1995; Echelmeyer and others, 1996; Fountain and Jacobel, 1997; Welch and others, 1998). 
Despite the increased penetration, the large wavelengths involved leave little but a bottom profile to be interpreted in the record. Consequently, it would be desirable to exceed $100 \mathrm{~m}$ of signal penetration depth at much higher frequencies, and to be able to do so with good lateral and vertical resolution.

Our radar methods are modifications of 3-D seismic survey practices (Claerbout, 1976; Schneider, 1978; Stolt, 1978) that have been adapted for the radiation characteristics of GPR antennas, and to meet the practical constraints of GPR surveys, namely, the need to keep data-collection and data-processing costs within reasonable bounds. Schneider (1978) applied the 3-D Kirchhoff method using stacked common midpoint seismic data. There have since been many examples of 3-D migration in reflection seismology. Typically, seismic studies collect vast datasets with complexly arranged source and receiver arrays (Stone, 1994). The cost of such studies is roughly two orders of magnitude larger than the cost of this study. In the comparatively restrictive operational context of GPR surveys, direct application of 3-D seismic methods is difficult to justify. Recent seismic migration innovations have concentrated on the difficult task of combining wave-speed model determination with migration. Fortunately, in glacier studies, radar wave propagation speed is essentially constant, and large quantities of monostatic data can be collected quickly.

Multidimensional GPR processing of glacier radar data has been performed in a limited number of cases. Fisher and others (1989) processed aerial Scott Polar Research Institute radar data (Evans and Smith, 1969) with 3-D array techniques to define the bottom topography of the central Greenland ice sheet. However, the narrow-bandwidth/longduration radar signal and aerial data-collection method are not practical for small-scale radar profiling, and migration using bottom return-time picks is inappropriate for determining the characteristics of the bottom reflections and the structure of the basal ice zone. On Storglaciären, Sweden, Walford and Kennett (1989) used a bi-static, $6 \mathrm{MHz}$ shortpulse transmitter/receiver $(\mathrm{Tx} / \mathrm{Rx}$ ) system to construct a single, three-component synthetic-aperture array. They used a low-population (100 elements) array with a comparatively small aperture $(50 \mathrm{~m}$ by $50 \mathrm{~m}$ ) and applied time-domain Kirchhoff processing to image in a 3-D volume. The results noted anomalies that suggested cavernous water inclusions at depths of $75 \mathrm{~m}$. Hamran and Aarholt (1993) used wavenumber-domain synthetic-aperture radar (SAR) (a method also called diffraction tomography) on subpolar glaciers. Diffuse scattered events in their records from water inclusions were imaged to depths of $200 \mathrm{~m}$ with $300-370 \mathrm{MHz}$ radar. Although an ice-rock interface was interpreted to $200 \mathrm{~m}$ with a 5-20 $\mathrm{MHz}$ radar, it is difficult to judge how well this interface was defined. Recently, Welch and others (1998) processed $5 \mathrm{MHz}$ GPR profiles collected on a tightly spaced orthogonal antenna grid. They used standard 2-D seismic migration methods to map a reflection surface directly under the data-collection surface. The 2-D migrated sections were then migrated again in the third dimension by reapplication of the standard 2-D wavenumber method. They also showed that arrays allowed resolution of bed features smaller than the Fresnel zone. Fountain and Jacobel (1997) also collected multiple GPR survey lines and applied 2-D migration. They used widely separated survey lines, predominantly oriented transverse to the direction of ice flow. They were able to define a bed-reflection topography for most of South Cascade Glacier, Washington, U.S.A., by applying standard 2-D frequency-wavenumber seismic migration methods. However, both Fountain and Jacobel (1997) and Welch and others (1998) note that record reflections can originate from out-of-plane regions that are not localizable by 2-D array processing. As will be shown, depth estimates from 2-D migration can contain substantial errors when applied to a steeply dipping valley glacier bed.

In the context of characterizing a temperate glacier with radar, the goals of this study are to demonstrate that practical 3-D data acquisition and array-processing methods remediate the associated problems of high clutter and shallow signal penetration, and that these methods allow true spatial localization of reflections. We accomplish this by synthesizing a dipole array, which forms a steerable, narrow, flashlight-like beam pattern that preserves the short-duration wavelet properties inherent in each element. The theoretical resolution attributes of our approach are reported in Moran and others (2000). That paper uses synthetic data with high noise levels to show that the signal-to-noise-ratio (SNR) improves dramatically with higher migration dimensionality, and that discrete scatters can be accurately localized outside the array coverage region. In the present work, these methods are applied to real data and the performance improvements are discussed and analyzed. The $50 \mathrm{MHz}$ dataset was collected on a grid on the northeast branch of Gulkana Glacier, located in the central Alaska Range (Fig. 1). At this site the valley walls were steep and easily approached and suggested a complex bottom topography that was nearly ideal for showing the reflection-localization capabilities of 3-D arrays. We supple-

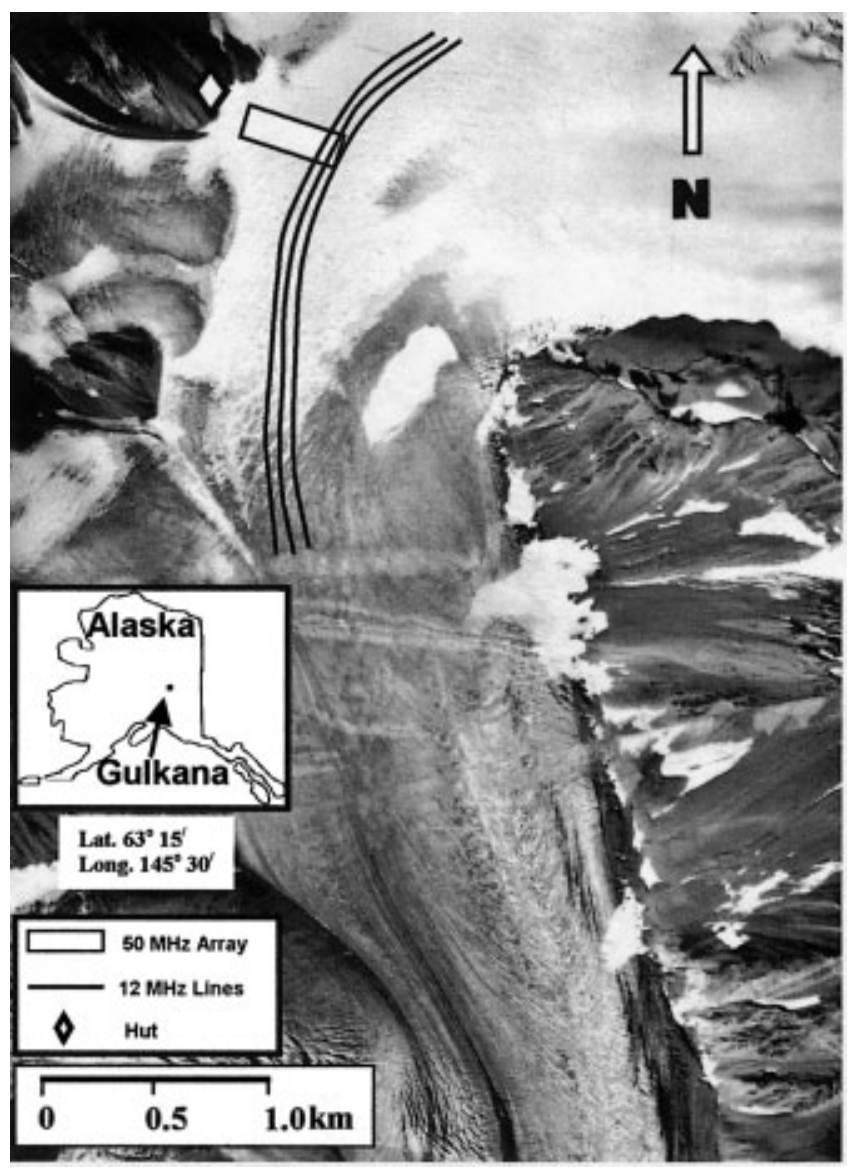

Fig. 1. Aerial photograph of Gulkana Glacier with schematic of GPR survey lines. The $100 \mathrm{~m}$ by $340 \mathrm{~m}, 50 \mathrm{MHz}$ GPR array is the rectangular box slightly to the left and below the U.S. Geological Survey hut. 
mented our grid survey with $400 \mathrm{MHz}$ profiles to help define our noise field, and $12 \mathrm{MHz}$ profiles to verify the character of the bed dip.

\section{RADAR EQUIPMENT}

\section{0 and $400 \mathrm{MHz}$ system}

Our data were collected using a commercial GPR system (also known as impulse, short-pulse, transient, carrier-free, sinusoidal or monocycle radar). The operation of this system has been described previously (Arcone, 1995; Arcone and others, 1995). The 16-bit control unit sets the pulse-repetition rate, trace parameters and time-variable gain function. The $400 \mathrm{MHz}$ antenna transducers were commercially manufactured. They are backshielded, resistively loaded dipoles with $15 \mathrm{~cm}$ separation. The transmitter excites an $8 \mathrm{~W}$ peak power pulse on the antenna. The $50 \mathrm{MHz}$ dipole antennas were developed in-house using a string of resistors. These antennas were unshielded and separated by $2.9 \mathrm{~m}$. When collecting $50 \mathrm{MHz}$ data we used a transmitter with $800 \mathrm{~W}$ peak power. Both antenna systems were towed behind a snow machine and were polarized with their antenna axes transverse to the profile direction.

\section{$12 \mathrm{MHz}$ system}

The $12 \mathrm{MHz}$ system is similar to other non-commercial constructions based on digitizing oscilloscopes (Jacobel and others, 1988; Jones and others, 1989). The receiver is an eight-bit Tektronix model 524A digital oscilloscope. The commercially available transmitter (Narod and Clarke 1994) generates high-power $(2.5 \mathrm{~kW})$ pulses at 512 repetitions per second in synchronous operation with the oscilloscope. The antennas are $10 \mathrm{~m}$ long resistively loaded dipoles arranged (and polarized) in a co-linear mode for easy towing. Their center-to-center separation was $20 \mathrm{~m}$. The receiver antenna was connected to the oscilloscope with fiber optics to avoid cable interference with the antenna radiation.

\section{Antenna patterns}

Theoretical far-field antenna radiation patterns in ice for resistively loaded dipoles of finite size are given by Arcone (1995) and Arcone and others (1995). The patterns apply to the far field regardless of antenna orientation (parallel/opposing or parallel/co-linear) so long as the separation is a small fraction of the far-field survey depth. The patterns are irregular in the vicinity of the critical angles of $34^{\circ}$ $\left(\sin ^{-1}(1 / n)\right.$, where $n=1.78$ is the refractive index of ice and the angle is measured from vertical).

In ice, far-field beam patterns form within $1 \mathrm{~m}$ range at $400 \mathrm{MHz}$, by $20 \mathrm{~m}$ at $50 \mathrm{MHz}$, and by $80 \mathrm{~m}$ at $12 \mathrm{MHz}$. The patterns in both the E-plane (the electric field within this plane is parallel to the axis of the dipole) and the perpendicular H-plane (magnetic field) have wide angles of sensitivity, but the H-plane patterns have much greater power near, and at, the critical angles. Therefore, our $12 \mathrm{MHz}$ co-linear antennas had greater sensitivity transverse to the direction of profiling, whereas our 50 and $400 \mathrm{MHz}$ antennas had greater sensitivity along the profile direction. The directivity $(F(\theta, \phi))$ of an infinitesimal dipole (Engheta and others, 1982; Arcone, 1995) is incorporated into our migration model because it approximates well the pattern for finite-size dipoles and it has a closed-form solution. However, the directivity achieved by a large aperture array is far narrower than $F(\theta, \phi)$ and precludes concern as to the exact form of $F(\theta, \phi)$ beyond a few degrees off the center axis of the array beam.

Analytical far-field expressions for interfacial dipole radiation have a 1/range dependency for the beam's geometric spreading loss, and a null pattern along the surface. However, it is well known (Brekhovskikh, 1960; Budden, 1960; Annan, 1973; Clough, 1976) that near-field 1/range ${ }^{2}$ dependency terms exist along the surface and produce both ground waves traveling at the ice speed and lateral waves traveling at the air speed. Characteristic of surface wave propagation, these laterally propagating airwaves continually refract energy into the ice at the critical angle, which is then prone to scattering from near-surface inclusions.

\section{SITE DESGRIPTION}

Gulkana Glacier is a small temperate valley glacier on the western slope of the central Alaska Range. It is easily accessible by snowmobile from the Richardson Highway. Gulkana Glacier has been well studied (Péwé and Reger, 1983), especially as part of a long-term mass-balance investigation (March and Trabant, 1996). We operated in the upper $2 \mathrm{~km}$ of the main branch of Gulkana Glacier (Fig. 1), which is within the ablation zone (no firn cover). Most of the accumulation occurs in and above several tributary icefalls feeding into the main branch. Gravity (Ostenso and others, 1965) and point radar soundings at $5 \mathrm{MHz}$ (unpublished data from D. C. Trabant, Geophysical Institute, Fairbanks, Alaska) suggested that maximum depths in the main branch are approximately $300 \mathrm{~m}$. Echelmeyer and others (1996) report that the elevation of Gulkana Glacier in this area has changed little in 50 years (an average decrease of about $11 \mathrm{~m}$, despite severe recession of the terminus). Their data, along with those of Sellmann (1962) and Rutter (1965), provided a check on the relative elevations measured in this study. The snow cover was generally $2 \mathrm{~m}$ deep and appeared dry at the time of our surveys (early April).

In choosing the array site we sought a location with a safe, smooth surface abutting a valley wall where the bottom topography deepened gradually in the cross-valley direction. These conditions are desirable for demonstrating improvements in clutter suppression and depth of penetration. Reconnaissance data collected at the base of a rock slope near the U.S. Geological Survey hut (Fig. 1) showed a gradually deepening bottom return that was undetectable by about 120 $140 \mathrm{~m}$ depth. The surface of the snow was smooth and apparently safe. The selected data-collection area was groomed with the snowmobile. This facilitated towing of the radar-operator sled and antennas. We did not expect till layers or large englacial conduits in upper reaches of the glacier. Also, the smooth, relatively flat surface of the glacier gave no indication that significant 3-D bed topography was present.

\section{DATA ACQUISITION}

We established a $100 \mathrm{~m}$ by $340 \mathrm{~m}$ regularly spaced array grid using a laser theodolite. The $100 \mathrm{~m}$ wide $x$ dimension was oriented in the down-glacier, southerly direction. The $340 \mathrm{~m} y$ dimension was oriented transverse to ice flow, in a roughly easterly direction. The western end $(y=0 \mathrm{~m})$ of the array was closest to the hut. We located station markers at $10 \mathrm{~m}$ intervals in $x$ and $20 \mathrm{~m}$ intervals in $y$. The maximum 
surface-elevation difference within the array grid was $18 \mathrm{~m}$, with the dominant elevation gradient occurring along the $y$ axis of the grid.

The $50 \mathrm{MHz}$ data have a trace duration of $3400 \mathrm{~ns}$ (16bit, 1024 samples/trace). The $400 \mathrm{MHz}$ data have a trace duration of $400 \mathrm{~ns}$ (16-bit, 2048 samples/trace). The $12 \mathrm{MHz}$ records have durations of $8192 \mathrm{~ns}$ (eight-bit, 1024 samples/trace). These sample intervals give about 6,13 and 10 samples per wavelet cycle at 50, 400 and $12 \mathrm{MHz}$, respectively. Although the $50 \mathrm{MHz}$ data are mildly undersampled compared with typical intervals of ten or more points per wavelet, the data are not aliased in the frequency domain. We applied a time-variable gain to the 50 and $400 \mathrm{MHz}$ data during recording. In the $50 \mathrm{MHz}$ array data, all discernible signals of interest are contained in the first $2000 \mathrm{~ns}$ of the records. In the $12 \mathrm{MHz}$ survey, we applied a 32-fold stack to provide a recording rate of 16 traces per second. The 400 and $50 \mathrm{MHz}$ data were stacked only two- to threefold during the position-justification process.

Within the array grid we collected 51 parallel survey lines using the $50 \mathrm{MHz}$ antennas. Each line was separated by approximately $2 \mathrm{~m}$ and oriented along the $y$ axis of the grid (west to east). In addition, we collected $400 \mathrm{MHz}$ data on ten $y$-oriented parallel lines spaced $10 \mathrm{~m}$ apart. The $12 \mathrm{MHz}$ profiles discussed in this paper were obtained along a $100 \mathrm{~m}$ wide longitudinal corridor beginning near the maximum height of the main branch of the glacier (Fig. 1). Positions for the $12 \mathrm{MHz}$ profiles were obtained with a GPS system having $30 \mathrm{~m}$ accuracy.

Image degradation in 3-D migration is a complicated function of the distribution of antenna-position errors, wavelet center frequency and the focus position. Though our timedomain approach allows us to use spatial sample intervals larger than a wavelength, a conservative bound for the mean error in antenna positions would ideally be less than one-fifth of an in situ ice wavelength, or about $70 \mathrm{~cm}$ at $50 \mathrm{MHz}$. Fortunately, these error tolerances are mean values and need only be maintained across a spatial extent corresponding with the largest array apertures to be processed. For example, a single 3-D migration result may use several overlapping, $40 \mathrm{~m}$ by $60 \mathrm{~m}$ sub-arrays that "tile" over an area of $40 \mathrm{~m}$ by $300 \mathrm{~m}$. It is only within each sub-array that the sensor-position error tolerance needs to be maintained.

We used snowmobiles to tow the recording system and antennas at a nearly constant speed with a high trace-acquisition rate. Electronic position markers were entered in the record headers and then digitally justified to provide the same number of traces between recorded marker intervals. In the $50 \mathrm{MHz}$ array grid, the $y$-position accuracy was better than $20 \mathrm{~cm}$. Control over the $x$ location of each line was problematic because the slightly down-sloping glacier surface caused antenna sleds to track as much as $1 \mathrm{~m}$ off the desired $x$ position. We estimate our mean $x$ position error to be $<30 \mathrm{~cm}$. A more desirable antenna-positioning method could be made by incorporation of differential global positioning system (GPS) coordinates directly into digital record headers instead of simple markers. In such a system, individual antenna positions could be specified with errors of $<5 \mathrm{~cm}$.

\section{DATA PROCESSING}

Initial data processing using commercial software included slight low-pass filtering, background removal, position normalization and elevation corrections. The range gain used in recording the data was maintained during array processing. The raw data were justified to give ten traces per meter for both the 50 and $400 \mathrm{MHz}$ datasets. The $12 \mathrm{MHz}$ data were justified to give five traces per meter. Elevation corrections for the $12 \mathrm{MHz}$ profiles were obtained using single reading non-differential GPS with a position accuracy of roughly $30 \mathrm{~m}$.

\section{Deconvolution}

Multiple cycles in the raw $50 \mathrm{MHz}$ wavelets, attributed to weak multiple reflections between the surface and snow-ice interface (Arcone and others, 1995), were removed prior to migration using an optimum Wiener deconvolution filter (Yilmaz, 1987). The deconvolved data improved the temporal resolution of bottom reflections and englacial diffractions (Fig. 2). The deconvolved bed-reflection wavelet is characterized by three large, half-cycle, oscillations (negative, positive, negative). This bottom-reflection attribute is consistent throughout our dataset. The parameters that produced the largest variations in deconvolved results were the shaping wavelet, the level of pre-whitening (random noise) and the segment of data used to design the filter coefficients. The deconvolution filter coefficients were calculated by forming an autocorrelation matrix from a raw bed-reflection wavelet (with a $106 \mathrm{~ns}$ period) and shaping this with a zero-lag boxcar wavelet having an $11 \mathrm{~ns}$ period. The resulting coefficients are applied to all the $50 \mathrm{MHz}$ data. In several places the deconvolved data show closely spaced overlapping reflections. It is likely that these overlapping reflections result from multiple out-of-plane reflections arriving at nearly the same time.

\section{Array processing}

We imaged the subsurface using a slight modification of the time-domain Kirchhoff integral migration method given by Schneider (1978). The strength of the energy scattered from a subsurface point is given by

$$
U\left(R^{\prime}, t=0\right)=\frac{-1}{2 \pi} \int_{\hat{s}} F^{\alpha}(\hat{\phi}, \hat{\theta}) \frac{\partial U(\hat{\phi}, \hat{\theta}, \hat{t})}{\partial \hat{t}} \frac{\cos \hat{\theta}}{x \hat{R}^{\beta}} \mathrm{d} \hat{s},
$$

where $F(\hat{\phi}, \hat{\theta})$ is the range-normalized single dipole radiation pattern (Stutzman and Thiele, 1981), $U(\hat{\phi}, \hat{\theta}, \hat{t})$ are the GPR surface observations, $U\left(R^{\prime}, 0\right)$ is the desired image in the subsurface at $R^{\prime}$, and $\hat{t}$ is the two-way travel time (retarded time) from the subsurface image point to the sensor point. We treated the exponents $\alpha$ and $\beta$ as processing parameters because, currently, there is no theory that includes effects of transmitter and receiver radiation patterns or considers radiation pattern distortions ascribable to time-range gain. A systematic trial-and-error study on the $50 \mathrm{MHz}$ data gave $\alpha=2$ and $\beta=1.5$. It is likely that our values for these parameters are directly related to the time-range gain recorded with our data. Properties of this procedure for radar data are discussed by Moran and others (2000).

Our implementation of Equation (1) follows a syntheticaperture array approach. In a subsurface volume, a migration image is formed by evaluating Equation (l) at discrete voxels using data from a rectangular array of surface points, as shown in Figure 3. To image a $y$ - $z$ plane, a subset of the array data (sub-array) is first fixed with its center at some $x$ and $y$ position. The sub-array data are then used to image a portion of the $y$ - $z$ image plane. The sub-array is then 

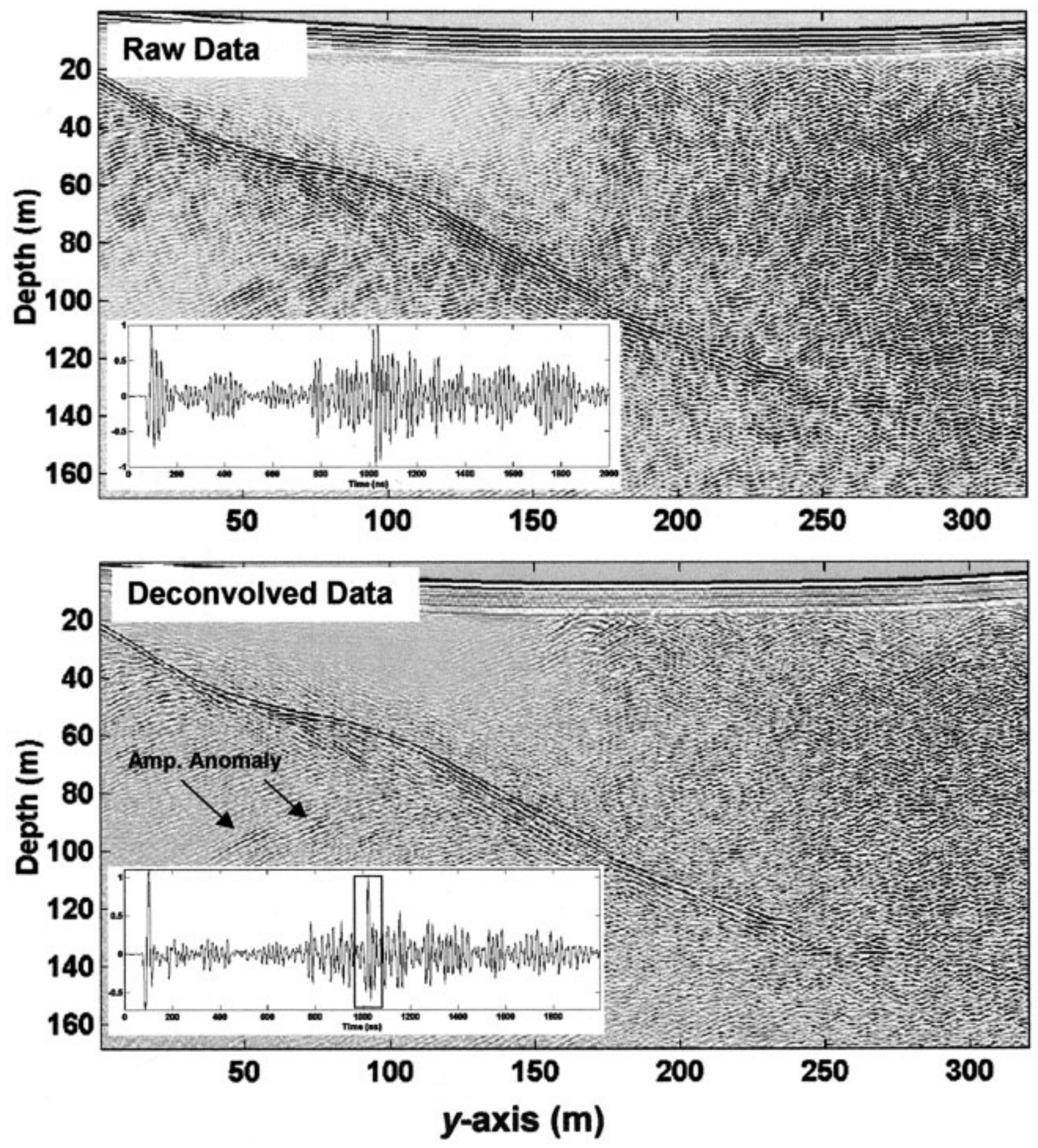

Fig. 2. Raw and deconvolved $50 \mathrm{MHz}$ profiles along $x=11 \mathrm{~m}$. The inset waveforms are taken from $y=150 \mathrm{~m}$. The boxed wavelet is the bed reflection. The deconvolved data show significant broadening of wavelet bandwidth. This improved the migration results. The prominent bottom reflections show many subtle out-of-plane influences, such as intermittent layer-like overlapping. Amplitude anomalies from out-of-plane reflections cause noise in migration results. The linear trends in the englacial clutter field are strong lateral waves.

moved, holding $x$ fixed, to greater $y$, and an additional portion of the $y-z$ plane is imaged. Generally, the two portions of the $y$ - $z$ plane have some overlap. In this overlap region the mean of the two results is taken. The center of the subarray is moved (along $y$ ) until the $y$ - $z$ image is completed. Sub-array apertures are generally about $40 \mathrm{~m}$ wide $(x$ dimension) by $60 \mathrm{~m}$ long ( $y$ dimension), and overlapped by $40-60 \%$ for successive $y$ positions. Figure 4 (explained in the Appendix) shows that these array dimensions result in a flashlight-like beamwidth of roughly $5^{\circ}$ and that the resolution of the migration process is comparable to that of a delay and sum beamformer (Capon and others, 1969). Using overlap between sub-arrays reduces edge effects between imaged portions in the fully formed $y-z$ image plane. To image an $x-z$ plane the same procedure is used, with the $y$ of the array center held constant as $x$ is increased for successive sub-array positions (Fig. 3). Further discussion of our array processing is given in the Appendix.

\section{RESULTS}

In cold-based glaciers, the ice-rock interface produces large radar reflections. However, there are several ways that reflections from the bottom can be lost. The most important are: (1) loss of energy to scattering from englacial inclusions, (2) masking by englacial clutter, and (3) a bottom topography that does not reflect rays to the data-coverage region. 


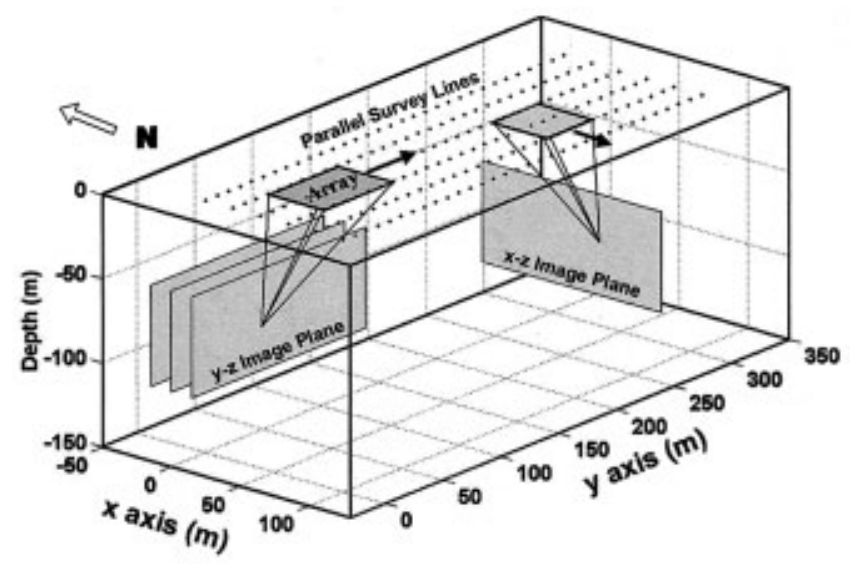

Fig. 3. Cartoon of our 3-D array and image-plane geometries. Data were collected continuously along a series of standard survey lines parallel to the $y$ axis. A synthetic-aperture array is defined by a sequence of sub-arrays arranged parallel to the $x$ or yaxis. A migration depth image is formed in a set of vertically oriented planes.

Although our data indicate that localized inclusions near the surface produced significant radar clutter, the 3-D array results show that loss of bottom reflections is principally caused by topographic changes in the bed surface. Our results also show significant improvement over 2-D migration methods.

\section{Near-surface ice-clutter characterization}

Near-surface ice inclusions and discontinuities, such as crevasses, produce radar clutter whose signature can extend deep into a record at arrival times similar to those of deep bed reflections. Aerial photographs (photo 87V2-186, Geodata Center, University of Alaska Fairbanks) from 1987 show that a complex system of narrow, crossing crevasses occurs in the area of our array grid. We use $400 \mathrm{MHz}$ profiles to characterize the upper $33 \mathrm{~m}$ of the ice. They show a $2 \mathrm{~m}$ thick snow layer and clusters of hyperbolic point diffractions under the eastern two-thirds of our grid (Fig. 5);
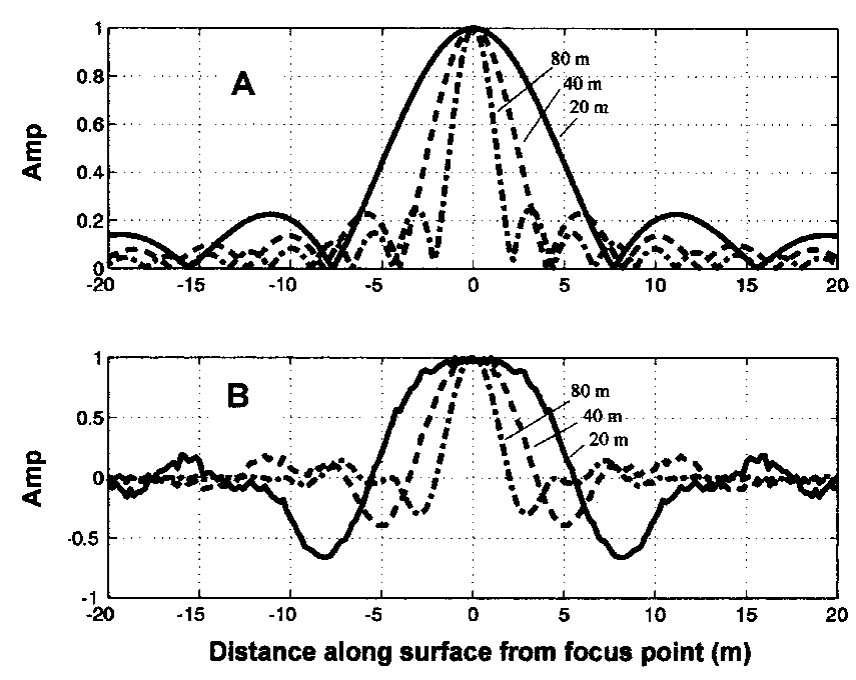

Fig. 4. 2-D linear-array beam response vs focus position for an isotropic point reflector buried $100 \mathrm{~m}$ below the array center $(d=0)$. (a) Frequency-domain beam pattern and ( $b)$ migration reflector strength vs focus position. In both results the array lengths are given on each curve and the inter-element array spacing is $2 \mathrm{~m}$. In all cases, the $-6 \mathrm{~dB}$ beam width is $<5 \mathrm{~m}$.

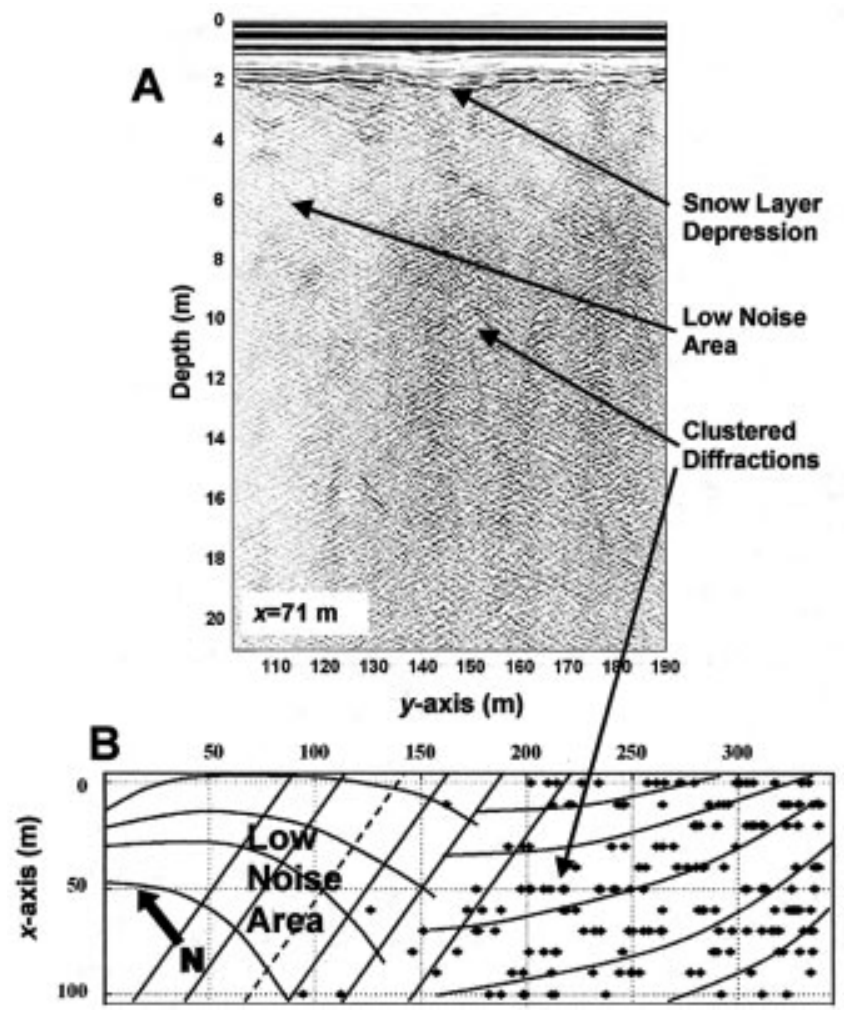

Fig. 5. Typical section of a $400 \mathrm{MHz}$ record ( a), which shows densely clustered point-diffraction hyperbolas, all of which migrate at the ice velocity $\left(\varepsilon_{\mathrm{r}}=3.17\right)$. They are generally distributed along 20-40 m wide swaths ( $b$ ) and are likely to be associated with the crossing pattern of crevasses ( $b$ ), as interpreted from aerial photography. Prominent scattering is not observed in the western third of the grid.

most of the hyperbolae reside in the upper $20 \mathrm{~m}$ of the ice. In general, these diffractors are associated with broad but modest depressions in the radar reflection horizon associated with the base of the snow layer. This would be expected when profiles cross narrow open crevasses at oblique angles. No snow-layer radar depressions are seen in the western end of the grid. At all depths, 2-D migration using the ice-propagation speed $\left(\varepsilon_{\mathrm{r}}=3.17\right)$, collapses the hyperbolae to points. This result implies that a significant fraction of our englacial noise originates from localized disturbances within the top $20 \mathrm{~m}$ of ice, and that the ice radar velocity is not impacted by the groomed snow surface. There is no evidence in the $400 \mathrm{MHz}$ ( or $50 \mathrm{MHz}$ ) data of interconnection between diffractors across the grid (i.e. linear patterns) or of phase changes from voids or conduits (Arcone and others, 1995). Both the 400 and $50 \mathrm{MHz}$ data, the ice underlying the western third of our grid, are relatively free of clutter (Figure 5). This is, in part, due to the lack of open crevasses in this region. The few weak diffractions originating in this zone also show hyperbola geometries characteristic of $\varepsilon_{\mathrm{r}}=3.17$. This clear ice extends to the bedrock, at about $30-38 \mathrm{~m}$ in this zone.

In contrast with the far-field diffractions seen at $400 \mathrm{MHz}$, a dominant noise feature in the $50 \mathrm{MHz}$ data (e.g. Fig. 2) is manifested by lateral waves. This noise is composed largely of numerous resonant events having a linear move-out of approximately $0.15 \mathrm{~m} \mathrm{~ns}^{-1}$. This is nearly the two-way propagation speed of air. These returns can be explained as laterally propagating airwaves, which continually refract into the ice (Clough, 1976; Arcone, 1984). The refracted airwaves are scattered back to the receiver by 


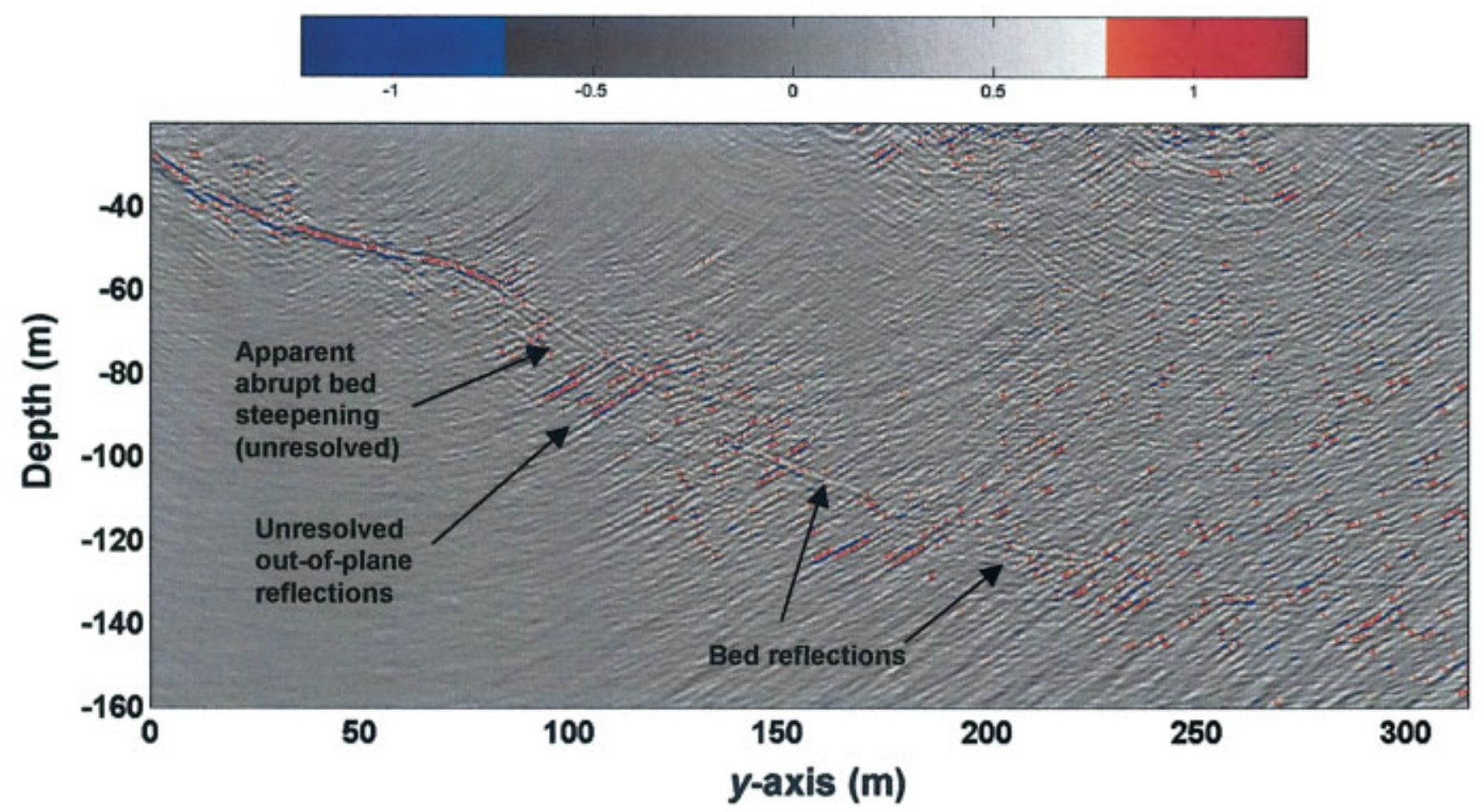

Fig. 6. 2-D migration result along $x=11 \mathrm{~m}$. Large-and small-amplitude anomalies from out-of-plane rejections have not been properly localized, and have also become poorly resolved, arching smears of energy. This result used six linear sub-arrays; each has a $60 \mathrm{~m}$ aperture with 600 elements. Each sub-array overlapped the next by $17 \%$.

near-surface discontinuities. Analogous phenomena are observed in seismic surveys (Larner and others, 1983). Lateral waves scattered from linear discontinuities (such as crevasses) at oblique angles will exhibit move-out velocities that are faster than airwave speeds (Clarke and Bentley, 1994). These are not seen in the $50 \mathrm{MHz}$ data. Therefore, we believe our $50 \mathrm{MHz}$ clutter was caused primarily by volumetric scattering from the localized shallow inclusions seen at $400 \mathrm{MHz}$.

\section{Delineation of bottom topography}

\section{2-D array results}

Traditional 2-D migration attempts to position all reflections in a vertical plane directly below the survey line. A 2-D $y-z$ plane depth image from our data is shown in Figure 6. In the coordinate system of the array grid, the line position was along $x=11 \mathrm{~m}$. The image shows many large- and smallamplitude circular "smears" in the depth image, which result from a strong noise field (Yilmaz, 1987, p. 274) and high-amplitude late arrivals in the time series (Fig. 2). Our 3-D results will show that these high-amplitude late arrivals are most likely out-of-plane reflections and are not properly localized by summation along a 2-D hyperbolic time--space curve. Also apparent in Figure 6 is a large discontinuity in the bed reflection in the interval, $75 \mathrm{~m}<y<130 \mathrm{~m}$. This results from the large bed dip along the survey line and (as will be shown later) a substantive component of bed dip perpendicular to the survey line. In such cases reflected rays intersect the surface outside the survey line, and 2-D processing is sufficient to resolve or correctly position the bed reflections.

Exploding-reflector-ray theory can partially explain the poorly resolved bed reflections from steep in-plane dips in 2D migration results. Rays originating from regions of steep dip will generate low-density ray patterns (shadow zones) on the surface and have longer path lengths. The longer travel paths imply larger scattering losses, and the high angles of ray incidence at the surface may lie outside major lobes of the dipole beam pattern. These factors cause recorded bedreflection amplitudes to be lower, and noise levels higher. This can account for many of the 2-D imaging degradations seen in Figure 6. However, if there are out-of-plane dip components (particularly in regions of steep dip) then 2-D migrations will fail to resolve the bed reflection, even though the raw-data records show high signal levels.

\section{3-D array results}

The 3-D array processing allows correct spatial positioning of reflections in $x, y$ and $z$. As we shall show, in some circumstances reflectors can be correctly positioned outside the data-coverage area. Depth images for a sequence of four parallel $y-z$ planes are given in Figure $7 \mathrm{a}-\mathrm{d}$. The images are generated from a single 3-D array that combined ten parallel survey lines. The array has a $6 \mathrm{~dB}$ beamwidth of $<6^{\circ}$ in $x$ and $3^{\circ}$ in $y$. In each image plane there are largeamplitude reflections from normally oriented facets of the bed. The relatively undistorted wavelets (compared to bedreflection wavelets in Figure 2) associated with the prominent reflections indicate that the array has been properly focused. Within any given slice, the brightest reflections abruptly diminish as the array focus shifts along $y$ or $x$ (between images). The sharp bed termination in both the longitudinal and transverse directions demonstrates that the array processing is spatially suppressing highly coherent, large-amplitude reflected bed energy. This characteristic is similar to very narrow, flashlight-like, theoretical beamformer results (Capon and others, 1969). Figure 7e is a composite that superimposes each major reflection onto a single projection. It shows that a nearly continuous bed surface has been mapped out.

Figure 8 shows four parallel $x$ - $z$ image planes produced from a single 3-D array result. Each image plane shows a coherent reflector between $15 \mathrm{~m} \leq x \leq 45 \mathrm{~m}$ with depths of 108-122 m. The image plane directly under the center line of 

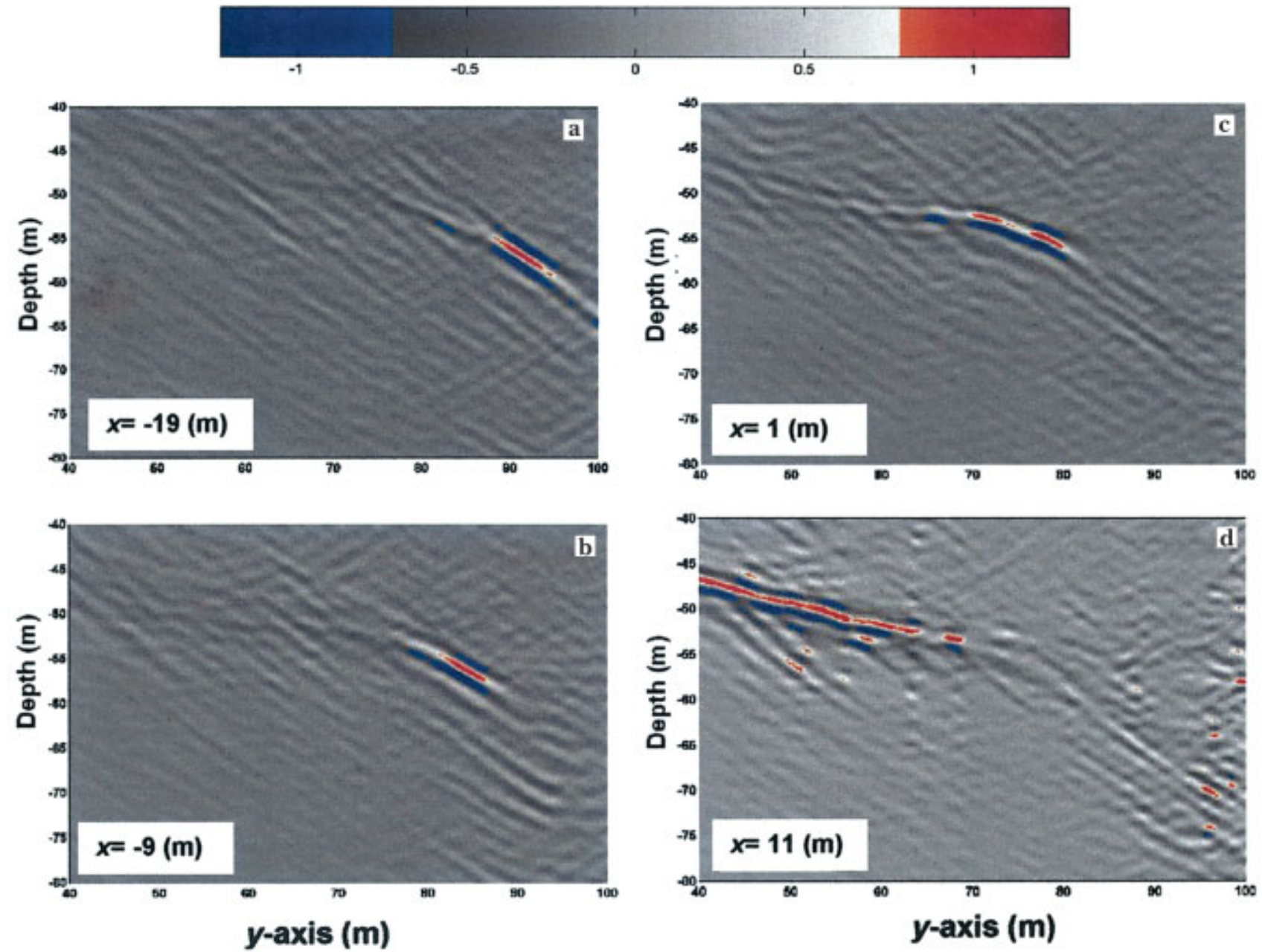

Fig. 7. Four $(a-d)$ parallel $y$-z plane image slices generated from a single 3-D array centered along $x=11 \mathrm{~m}$. The prominent reflections occurring at various positions demonstrate localization of out-of-plane normal reflections. (e) Composite of all four reflections projected onto a single $y$-z plane. The results used a sub-array aperture of $20 \mathrm{~m}$ (in $x$ ) by $40 \mathrm{~m}$ (in $y$ ) with 671 elements, each separated by $2 m$ and $1 m$ in $x$ and $y$, respectively. Two sub-arrays covered the data interval between $0 m \leq y \leq 120 \mathrm{~m}$.

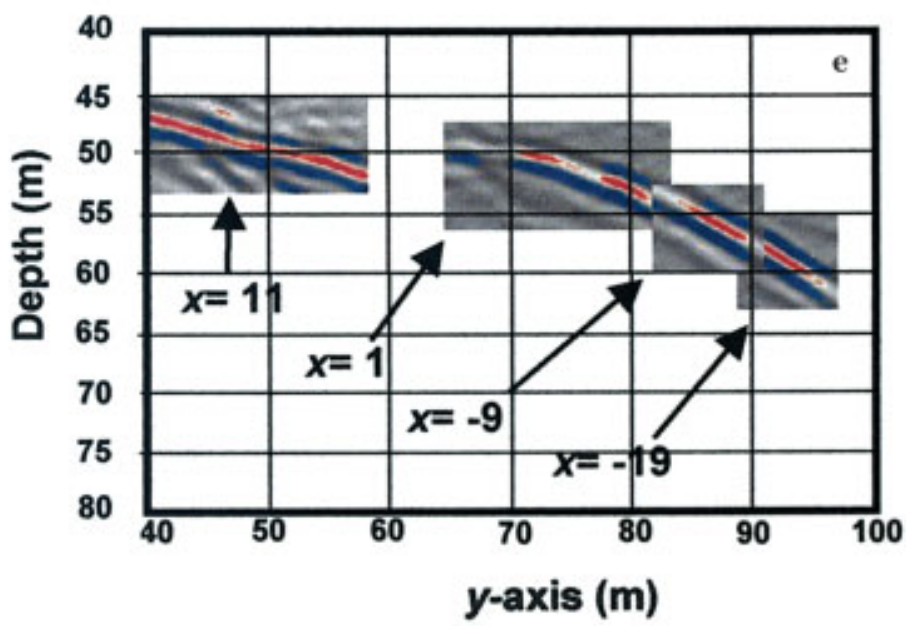

the array ( $y=175 \mathrm{~m}$; Fig. 8d) shows an abrupt loss of focus and amplitude at roughly $x=40 \mathrm{~m}$ at $120 \mathrm{~m}$ depth. Later discussion will show that the bed slope abruptly increases (in the down ice-flow direction) in this region. In expectation of observing reflections from the up-dip (lower $x$ ) direction, we extended the image-plane boundaries to $x=-30 \mathrm{~m}$. In Figure 8a $(y=145 \mathrm{~m})$ there is a distinct normal reflection at $x=-20 \mathrm{~m}$ at $95 \mathrm{~m}$ depth. The loss of reflector continuity between this event and that imaged at $x=20$ m must be caused by a steeply dipping slope in this region. The depth images in Figure 8 also contain low-amplitude, poorly focused reflection smears that result from poor sensor positioning in the $x$ direction, and edge effects produced by limited array coverage. Relative sensor-position error within a sub-array introduces a slight misalignment of bed-reflection arrival times in the hyperbolic time--space summation performed in the Kirchhoff integration. This results in in-

complete signal cancellations as the focus point is shifted away from a normal reflection point on the bed. Edge effects will be seen when there is insufficient array coverage for positioning a normal reflection. In this example, extending the array coverage farther in $x$ would improve image quality.

We systematically applied 3-D migration over the entire data grid, and normal reflections were picked from the results. We fit a bi-cubic spline surface through these data to produce a topographic surface of the glacier bed (Fig. 9). The maximum resolved depth is roughly $140 \mathrm{~m}$ at $y$ values of $>250 \mathrm{~m}$. The surface contains significant dip components in both the $x-z$ and $y$ - $z$ planes. There is a blank region at $x>$ $75 \mathrm{~m}$ where no reflections were observed. The open circles plotted on the bed are reflection points picked from several $y$ - $z$ depth slices for sub-arrays positioned along $x=35 \mathrm{~m}$. The lines projecting from the bed-reflection points connect to the surface sub-array positions that received that particu- 

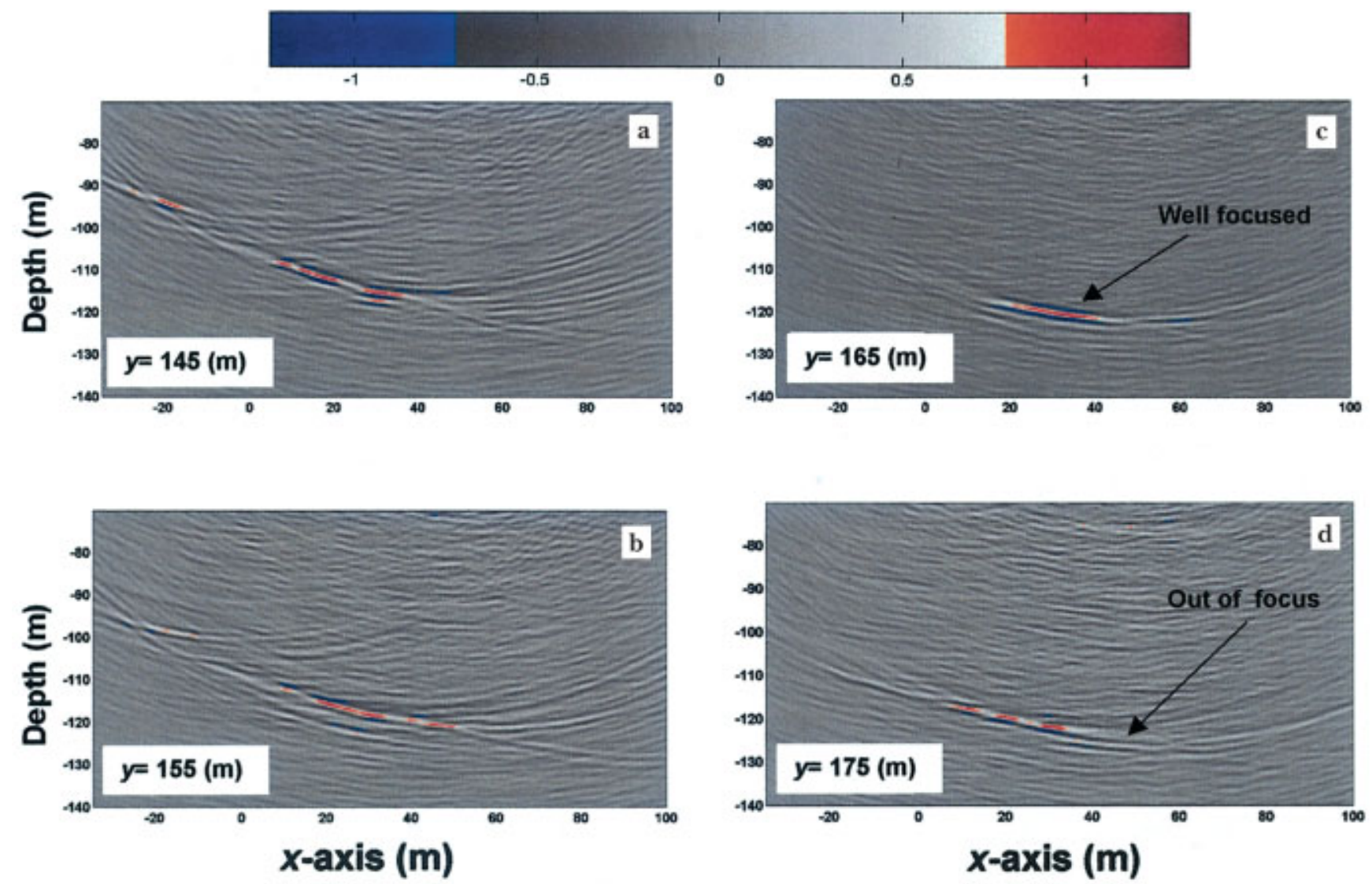

Fig. 8. A sequence of four parallel $x$-z plane depth images generated from a single 3-D array run. All the images show well-resolved bottom reflections. The abrupt loss of the dominant reflector beyond $x=40 \mathrm{~m}$ is caused by an increase in the $x$ component of the bed slope. (a) shows a normal reflection originating from $x=-20 \mathrm{~m}$ at roughly $94 \mathrm{~m}$ depth. The results used two sub-arrays with apertures of $60 \mathrm{~m}$ (in $x$ ) by $40 \mathrm{~m}$ (in y) centered along $y=175 \mathrm{~m}$. The overlapwas $40 \%$. Sub-array sensor spacing was $2 \mathrm{~m}$ (in both $x$ and $y$ ), giving 600 elements.

lar normal reflection. Thus, these lines can be thought of as representing exploding reflector rays.

\section{Comparisons of 3-D, 2-D and raw-data depth profiles}

In radar reflection environments such as Figure 9, there will be substantial error in depths determined from either raw data or 2-D migration. To quantify these errors, a topographic surface was constructed from the 2-D migration-bed profiles. This was subtracted from the 3-D topographic surface determined from our methods. The resulting difference surface is shown in Figure 10. The region of largest disagreement between the 2-D and 3-D surfaces follows a diagonal trend, where the steepest slopes $\left(45^{\circ}\right)$ occur in both surfaces. The maximum difference is roughly $14 \mathrm{~m}$. In all locations the depth profiles from the raw data and the 2-D migrations are shallower than depths determined using the 3-D array. The 3D profiles are consistent with classic " $U$ "-shaped cross-valley profiles, whereas the 2-D and raw-data profiles indicate more gently dipping surfaces. In the regions of steepest dip (around $y=100 \mathrm{~m}$ ), the disagreement between the 3-D depth estimates and the 2-D and raw-data estimates is 14 and $35 \mathrm{~m}$, respectively. Using these differences in depth, and assuming the 3-D result to be correct (with a depth of $95 \mathrm{~m}$ ), implies that the 2-D depth estimate has a $15 \%$ error and the raw-data estimate has a $36 \%$ error.

In addition to correcting the depth errors, the bottom topography generated by the 3-D method extends outside the data-coverage surface in the up-dip direction and terminates well inside the data-coverage area in the down-dip direction. Specifically (in Fig. 10), at $x$ positions in the interval $-20 \mathrm{~m} \leq x \leq 1 \mathrm{~m}$, the 3 -D array has localized the reflecting surface, whereas the 2-D migration methods cannot position reflections in this region. In the interval $70 \mathrm{~m} \leq x \leq 100 \mathrm{~m}$ and $y>140 \mathrm{~m}$, the 2-D migrations position reflections directly below the survey lines, whereas the 3-D array results show no resolvable reflections. Given a deepening reflector

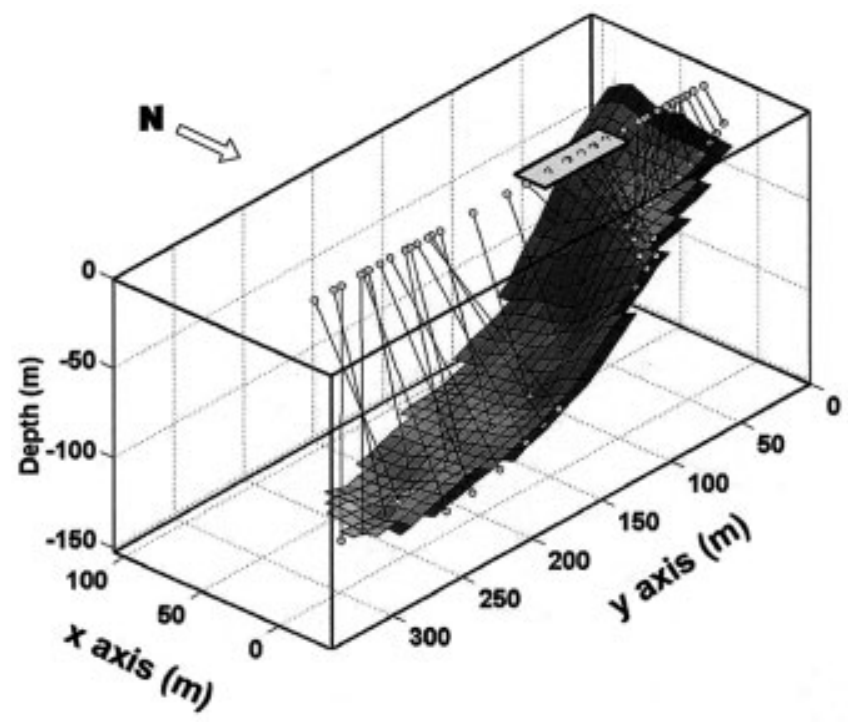

Fig. 9. Perspective drawing of the bed topography as determined by 3-D array results. The open circles on the surface of the bed are points picked from several 3-D y-z depth slices for a sequence of array runs along $x=35 \mathrm{~m}$. The lines projecting from the bed-reflection points connect with the position of the sub-arrays that observed the reflections. Thus, these lines can be thought of as the specular reflection ray paths. 


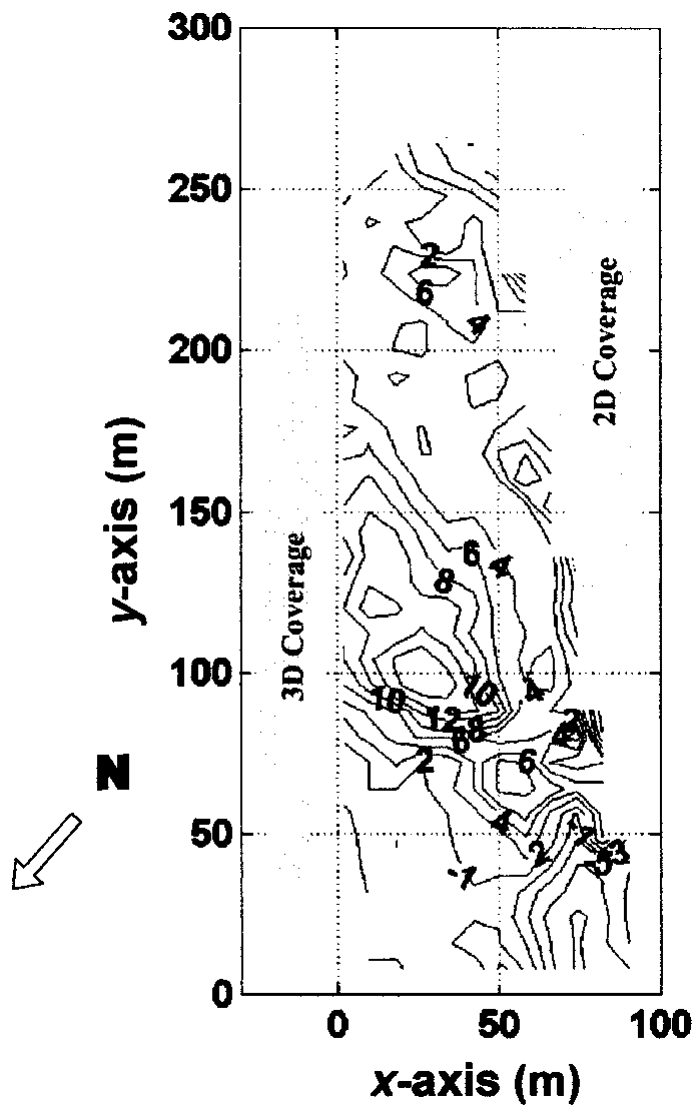

Fig. 10. Difference surface constructed from topographic surfaces generated by 2-D and 3-D array results. The maximum disagreement is roughly $14 \mathrm{~m}$. There are regions where the $3-D$ array results show no returns $(x>70 \mathrm{~m})$, whereas the $2-D$ array results erroneously place reflections in this region. At positions $x<1 m$ (shaded region on left), the 3-D results accurately position reflections outside the data-coverage area.

as $x$ increases, it is obvious that the reflections seen in the 2-D image are really located up-dip at lower $x$.

Independent quantitative support for the 3-D array results is given by $12 \mathrm{MHz}$ survey lines that cross the eastern end of the grid. Figure 1la gives the geometry for two of these lines (lines 15 and 35) in the coordinate system of the array grid. Figure $11 \mathrm{~b}$ shows the first $600 \mathrm{~m}$ of the 2-D migrated depth sections for lines 35 and 15. Line 35's depth section passes diagonally across the grid between $\mathrm{A}$ and $\mathrm{A}^{\prime}$. In this interval there is a steepening of the bed slope. Line 15's migrated section crosses the far eastern corner of the array grid in the interval labeled $\mathrm{B}-\mathrm{B}^{\prime}$. It too indicates an abrupt increase in bed dip under the grid. The $12 \mathrm{MHz}$ reflector depths are consistent with depth estimates determined from the $3-\mathrm{D}$ array processing. Although these $2-\mathrm{D}, 12 \mathrm{MHz}$ results are processing out-of-plane reflections, the effect is small relative to the wavelength. Thus, we are justified in using the general character of the $12 \mathrm{MHz}$ results to support our finding that steep dip in the down-flow direction resulted in the loss of bed reflections within the array grid.

\section{False-layering suppression and SNR improvement}

Suppression of reflections from outside the array beam increases SNR and reduces interpretation ambiguity. Figure 12 shows a side-by-side comparison of depth sections from 3 -D and 2-D migration. Both images are $y$ - $z$ planes located at $x=21 \mathrm{~m}$. The center line of the 3 -D array was located along $x=71 \mathrm{~m}$. This places the image plane $30 \mathrm{~m}$ up-dip (relative to $x=51 \mathrm{~m}$, the northernmost line used in the 3 -
$\mathrm{D}$ array). Both the 2-D and 3-D results used comparable sub-array parameters. In the 2-D migration the bed profile is discernible only by the intermittent, weak, but spatially coherent, amplitude variation that trends counter to the dominant noise field. This migration image also shows an apparent layer sequence, which could easily be interpreted as evidence of glacial till or debris-filled basal ice. These features were common in many of our 2-D migrations. However, none of our image slices from the 3-D array processing shows such layer structures. A possible explanation for the apparent layering is the superposition of two (or more) slightly out-of-plane bed reflections.

Relative to the 2-D migration image, the 3-D array image (Fig. 12) shows a bed profile with a much higher degree of spatial coherence and a higher SNR. Comparing the mean noise power to the mean bed-reflection power in the 2-D and 3-D results gives an SNR of 0 and $12 \mathrm{~dB}$, respectively. In the $3-\mathrm{D}$ result, the bed-reflection wavelet out to $y=$ $160 \mathrm{~m}$ is relatively undistorted, indicating good focusing. Beyond $y=160 \mathrm{~m}$, the reflector becomes less coherent and the wavelets show minor distortion. Repositioning of the image plane by as little as $5 \mathrm{~m}$ would bring this portion of the bed into better focus. Even with the slight focus problem, the 3-D array image convincingly contradicts the suggestion of layering seen in the 2-D migration image.

\section{CONGLUSIONS}

Using a $50 \mathrm{MHz}$ monostatic short-pulse radar system, we have demonstrated that full-wavefield, 3-D SAR processing is practical and adds important capabilities for characterizing cluttered temperate glaciers. Using many parallel survey lines oriented transverse to the ice flow, we produced depth images oriented both parallel and transverse to the direction of ice flow. Our analysis methods offer several important improvements: 3-D localization of all radar reflections, improved interpretation of bottom reflections, increased SNR against most types of noise, and increased depth of signal penetration. These improvements result from the development of a very narrow, steerable array beam pattern, and preservation of the short-duration wavelets characteristic of our electrically small broadband dipoles. Large cost savings and better imaging resolution can undoubtedly be obtained by automatic incorporation of differential GPS data directly into the digital radar data records.

Classic beamformer array processing broadly defines "noise" as any energy arriving from directions outside the focus point of the array. By this definition, even reflections from the glacier bed are considered "noise" (and are suppressed) if they do not originate at the focus point in an imaged plane. It is this mechanism that allows high-resolution localization of normally oriented facets of the bed. In the temperate-glacier context, 3-D array processing reduces clutter because, in a sense, the array beam "sees" only the scattering inclusions that lie in the image plane. All other forms of clutter, including reflected airwaves, englacial inclusions and out-of-image-plane bed reflections, are suppressed.

The 3-D array was able to resolve $45^{\circ}$ bed dips. The deepest reflections observed were at depths of $140 \mathrm{~m}$. We conclude that changes in topography resulted in loss of signal, not signal scattering from ice inclusions. Near the steeply sloping wall of the glacier, we found that interpretation of raw-data profiles underestimated depths by $36 \%$, and that 2-D migra- 

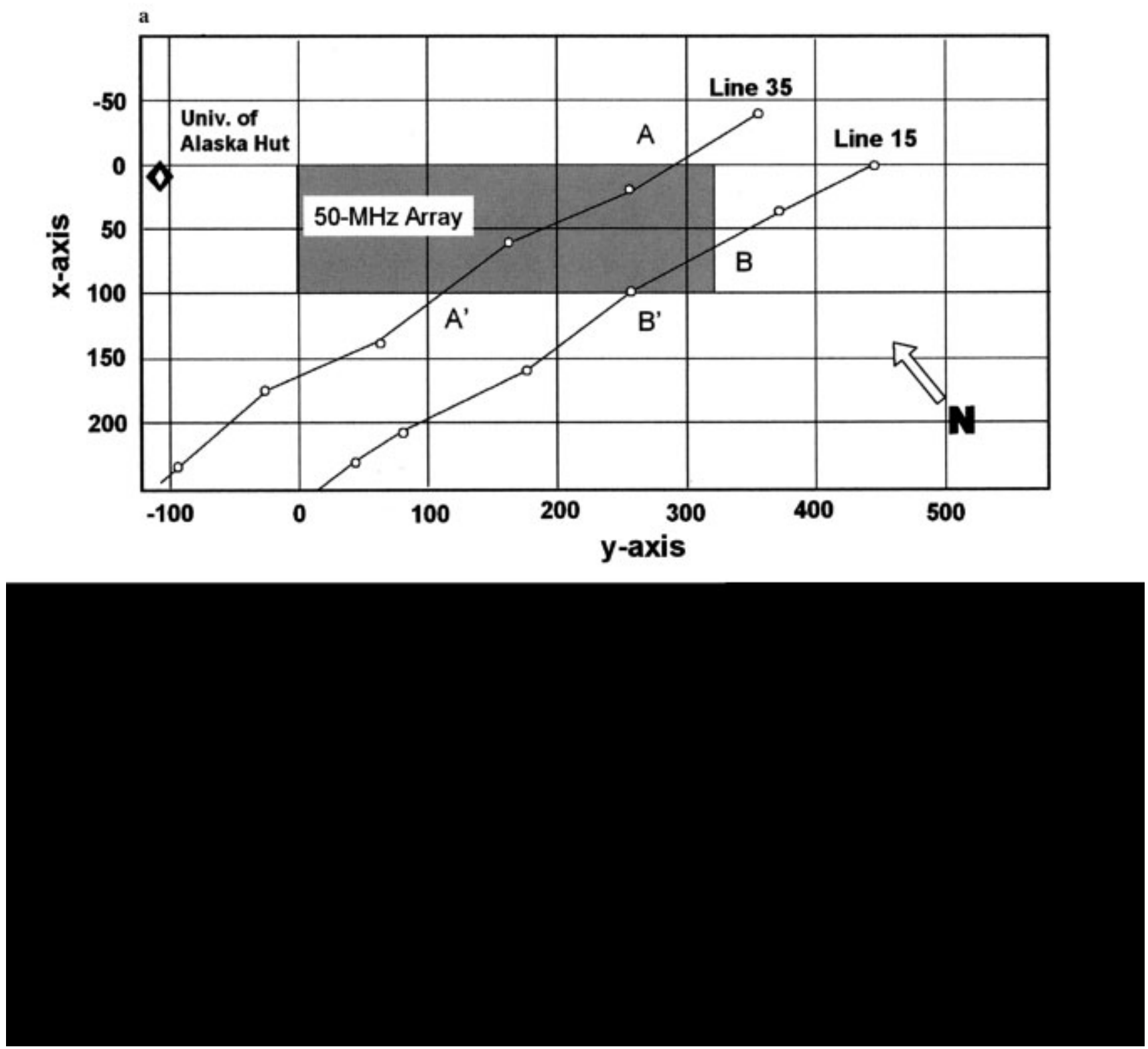

Fig. 11. (a) Layout of the $12 \mathrm{MHz}$ survey lines relative to the $50 \mathrm{MHz}$ array grid. The lines are generally parallel to the direction of ice flow. (b) $12 \mathrm{MHz}$, 2-D migrations along lines 35 and 15. Line 35 crosses the array grid diagonally between $A$ and $A^{\prime}$. The relative increase in bed slope at $190 \mathrm{~m}$ distance is roughly the rnidpoint of the array grid. The line 15 depth section crosses under the far eastern end of the array grid between $B$ and $B^{\prime}$. In this interval there is also a sudden increase in bed slope. This supports the 3 $D$ array results which show no bottom reflections originating in these regions of the array grid. Out-of-plane reflections are present in both sections, particularly before and after the steep dip sections.

tions underestimated depths by $16 \%$. Furthermore, 3-D array processing improved bed-reflection SNR by $>12 \mathrm{~dB}$, clearly bringing the reflector wavelet above the background noise level. Possible interpretation pitfalls such as mislocation of bottom geometry and false layering are clarified.

Though we have no direct evidence (such as drilling) to confirm our 3-D results, there is a high degree of internal consistency, and plausible, simple, physical explanations readily support our findings. For example: (1) reflection picks from many different sub-array positions formed a smooth continuous reflector surface; (2) the bottom topography is consistent with a classic "U"-shaped cross-valley profile, which is not seen in the 2-D results; (3) in the down-flow direction the bed surface has a reasonable dip profile; (4) we can only localize bottom reflections outside our arrays in the up-slope/up-flow direction; (5) with few exceptions, we cannot localize bottom reflections directly beneath our arrays, particularly at the southern end of the array grid (this is explained easily with simple ray theory and a dipping reflection surface); and (6) our resolved bottom signals are coherent wavelets with high SNR that have properties that fall well within resolution limits obtained from beamforming theory.

\section{AGKNOWLEDGEMENTS}

Support for this research was provided by the U.S. National Science Foundation (NSF grants OPP-9531800 and OPP9531579), by the U.S. Army Cold Regions Research and Engineering Laboratory (CRREL) project 4A161102AT24, work unit AT24-SS-E10, and the CRREL project 96-ILIR, titled "Signal Penetration Depth and Noise Suppression Improvement Using A Time Domain Radar Array".

We wish to express many thanks to L. Davis and P. Annan of Sensors and Software Inc., Mississauga, Ontario, Canada, for use of equipment and field assistance during data collection at Camp Borden. The Borden data were used 

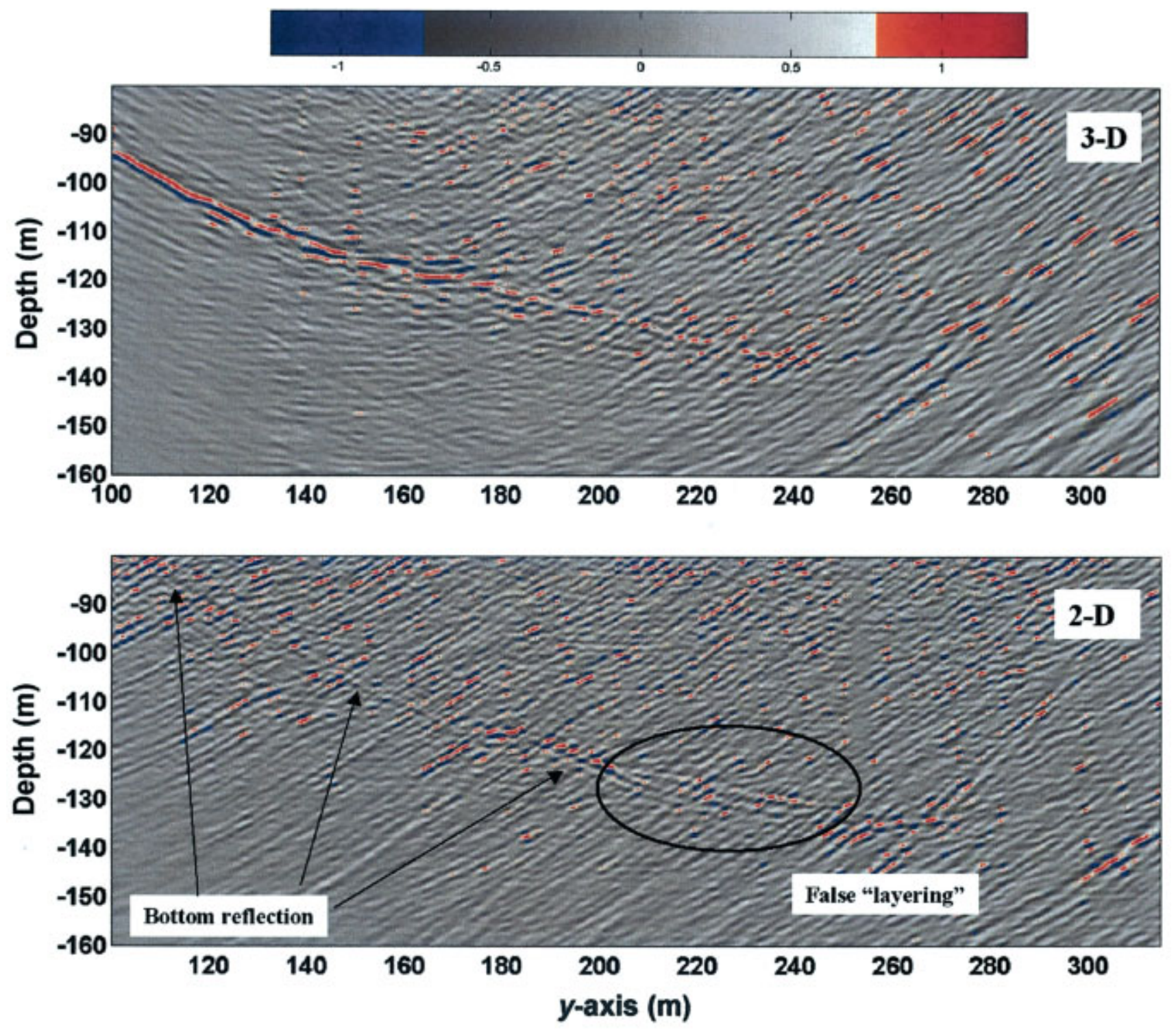

Fig. 12. Comparison of 3-D and 2-D y-z image planes along $x=21 \mathrm{~m}$. In the 2-D migration the bed reflection is barely discernible above the noise field and there is a false-layering effect caused by nearly coincident out-of-plane arrivals. No corresponding layering is seen in the 3-D depth section. The 3-D sub-arrays were positioned along $x=71 \mathrm{~m}$ and had aperture dimensions of $40 \mathrm{~m}$ (in x) by $60 \mathrm{~m}$ (in y) with sensors spaced at $2 \mathrm{~m}$ intervals, giving 600 elements. The 2-D result has a y aperture of $60 \mathrm{~m}$ with a sensor spacing of $0.5 \mathrm{~m}$, giving 120 elements. Both results used three sub-arrays overlapped by $17 \%$.

extensively in developing the methods applied in this paper. Further thanks go to G. Kuehn of Arete Training and Solutions, Hobart, Tasmania, Australia, for his professional support in providing glacier safety, base-camp management and technical services while collecting glacier radar data. Thanks go to the organizers of and participants in the 12th Annual Arctic Man Ski and Sno-Go Classic, 1997, for their consideration during our experiments.

\section{REFERENCES}

Annan, A. P. 1973. Radio interferometry depth sounding. Part 1. Theoretical discussion. Geophysics, 38(3), 557-580.

Arcone, S. A. 1984. Field observations of electromagnetic pulse propagation in dielectric slabs. Geophysics, 49(10), 1763-1773.

Arcone, S. A. 1995. Numerical studies of the radiation patterns of resistively loaded dipoles. 7. Appl. Geophys., 33, 39-52.

Arcone, S. A., D. E. Lawson and A. J. Delaney. 1995. Short-pulse radar wavelet recovery and resolution of dielectric contrasts within englacial and basal ice of Matanuska Glacier, Alaska, U.S.A. F. Glaciol., 41 (137), 68-86.

Blindow, N. and F. Thyssen. 1986. Ice thickness and inner structure of the Vernagtferner (Ötztal Alps): results of electromagnetic reflection measurements. Z. Gletscherkd. Glazialgeol., 22 (1), 43-60.

Brekhovskikh, L. M. 1960. Waves in layered media. New York, Academic Press Inc
Budden, K. G. 1960. The wave-guide mode theory of wave propagation. Englewood Cliffs, NJ, Prentice-Hall Inc.

Capon, J., R. J. Greenfield and R. T. Lacoss. 1969. Long period signal processing results for the Large Aperture Seismic Array. Geophysics, 34, 305329 .

Claerbout, J. F. 1976. Fundamentals of geophysical processing. New York, McGraw Hill Inc.

Claerbout, J. F. 1985. Imaging the Earth's interior. Oxford, Blackwell Scientific Publications.

Clarke, T. S. and C. R. Bentley. 1994. High-resolution radar on Ice Stream B2, Antarctica: measurements of electromagnetic wave speed in firn and strain history from buried crevasses. Ann. Glaciol., 20, 153-159.

Clough, J.W. 1976. Electromagnetic lateral waves observed by earth sounding radars. Geophysics, $\mathbf{4 1}(6 \mathrm{~A}), 1126-1132$.

Echelmeyer, K. A. and 8 others. 1996. Airborne surface profiling of glaciers: a case-study in Alaska. F. Glaciol., 42(142), 538-547.

Engheta, N., C. H. Papas and C. Elachi. 1982. Radiation patterns of interfacial dipole antennas. Radio Sci., 17 (6), 1557-1566.

Evans, S. and B. M. E. Smith. 1969. A radio echo equipment for depth sounding in polar ice sheets. F. Phys. E, 2(2), 131-136.

Fisher, E. and 6 others. 1989. Determination of bedrock topography beneath the Greenland ice sheet by three-dimensional imaging of radar sounding data. F. Geophys. Res., 94(B3), 2874-2882.

Fountain, A. G. and R.W. Jacobel. 1997. Advances in ice radar studies of a temperate alpine glacier, South Cascade Glacier, Washington, U.S.A. Ann. Glaciol., 24, 303-308.

Hamran, S.-E. and E. Aarholt. 1993. Glacier study using wavenumber do- 
main synthetic aperture radar. Radio Sci., 28(4), 559-570.

Harrison, W. D., K. A. Echelmeyer, E. F. Chacho, C. F. Raymond and R. J. Benedict. 1994. The 1987-88 surge of West Fork Glacier, Susitna Basin, Alaska, U.S.A. 7. Glaciol., 40(135), 241-254.

Jacobel, R.W., S. K. Anderson and D. F. Rioux. 1988. A portable digital data-acquisition system for surface-based ice-radar studies. F. Glaciol., 34(118), 349-354.

Jones, F. H. M., B. B. Narod and G. K. C. Clarke. 1989. Design and operation of a portable, digital impulse radar. F. Glaciol., 35(119), 143-148.

Larner, K., R. Chambers, M. Yang, W. Lynn and W. Wai. 1983. Coherent noise in marine seismic data. Geophysics, 48, 854-886.

Lønne, I. and T. Lauritsen. 1996. The architecture of a modern push-moraine at Svalbard as inferred from ground-penetrating radar measurements. Arct. Alp. Res., $28(4), 488-495$.

March, R. S. and D. C. Trabant. 1996. Mass balance, meteorological, ice motion, surface altitude, and runoff data at Gulkana Glacier, Alaska, 1992 balance year. U.S. Geol. Surv. Water-Resour. Invest. Rep. 95-4277.

Moran, M.L., R.J. Greenfield, S.A. Arcone and A.J. Delaney. 2000. Multidimensional GPR array processing using Kirchhoff migration. f. Appl. Phys., 43, 281-295.

Murray, T., D. L. Gooch and G. W. Stuart. 1997. Structures within the surge front at Bakaninbreen, Svalbard, using ground-penetrating radar. Ann. Glaciol., 24, 122-129.

Narod, B. B. and G. K. C. Clarke. 1994. Miniature high-power impulse transmitter for radio-echo sounding. F. Glaciol., 40(134), 190-194.

Nolan, M., R. J. Motyka, K. Echelmeyer and D. C. Trabant. 1995. Ice-thickness measurements of Taku Glacier, Alaska, U.S.A., and their relevance to its recent behavior. F. Glaciol., 41(139), 541-553.

Ostenso, N. A., P. V. Sellmann and T. L. Péwé. 1965. The bottom topography of Gulkana Glacier, Alaska Range, Alaska. 7. Glaciol., 5(41), 651-660.

Péwé, T. L. and R. D. Reger, eds. 1983. Guidebook to permafrost and Quaternary geology along the Richardson and Glenn highways between Fairbanks and Anchorage, Alaska. Fourth International Conference on Permafrost, July 18-22, 1983, University of Alaska, Fairbanks, Alaska. Fairbanks, AK, State of Alaska. Department of Natural Resources. Division of Geological and Geophysical Surveys. (Guidebook 3.

Rutter, N.W. 1965. Foliation pattern of Gulkana Glacier, Alaska Range, Alaska. 7. Glaciol., 5(41), 711-718.

Schneider, W. A. 1978. Integral formulation for migration in 2 and 3 dimensions. Geophysics, 43(1), 49-76.

Sellmann, P.V. 1962. Flow and ablation of Gulkana Glacier, Alaska. (M.Sc. thesis, University of Alaska Fairbanks.)

Skolnik, M. L. 1962. Introduction to radar systems. New York, McGraw-Hill.

Smith, B. M. E. and S. Evans. 1972. Radio echo sounding: absorption and scattering by water inclusion and ice lenses. F. Glaciol., 11 (61), 133-146.

Stolt, R. H. 1978. Migration by Fourier transform. Geophysics, 43(1), 23-48.

Stone, D. G. 1994. Designing seismic surveys in two and three dimensions. Tulsa, OK, Society of Exploration Geophysicists.

Stutzman, W. L. and G. A. Thiele. 1981. Antenna theory and design. New York, etc., John Wiley and Sons.

Trabant, D. C., B. F. Molnia and A. Post. 1991. Bering Glacier, Alaskabed configuration and potential for calving retreat. [Abstract.] EOS, 72(44), Supplement, 159.

Walford, M. E. R. and M. I. Kennett. 1989. A synthetic-aperture radioecho experiment at Storglaciären, Sweden. F. Glaciol., 35(119), 43-47.

Watts, R. D. and A. W. England. 1976. Radio-echo sounding of temperate glaciers: ice properties and sounder design criteria. F. Glaciol., 17(75), 39-48.

Welch, B. C., W. T. Pfeffer, J.T. Harper and N. F. Humphrey. 1998. Mapping subglacial surfaces of temperate valley glaciers by two-pass migration of a radio-echo sounding survey. f. Glaciol., 44(146), 164-170.

Yilmaz, Ö. 1987. Seismic data processing. Tulsa, OK, Society of Exploration Geophysicists. (Investigations in Geophysics 2.)

\section{APPENDIX}

\section{DISGUSSION OF 3-D ARRAY PROPERTIES}

The Kirchhoff integral in Equation (1) is evaluated over the surface containing sensor observation points. In 3-D array processing, Schneider (1978) notes that this procedure works by summing over a 3 -D hyperbolic time--space surface in data space. In 2-D applications, the integral is evaluated along a line, and the summation is along a hyperbolic time- space curve. When focusing at a spatial coordinate that contains a scattering inclusion, coherent energy will sum in phase and the signal level will be elevated. At focus locations where no scattering originates, the data summation is incoherent, resulting in a (relatively) reduced signal level.

The image formed by our migration procedure has much in common with the process of aiming direct sum beams at a subsurface point. For the common source-receiver configuration, the received energy has reflected from a specular point where the ray path of the signal is normal to the reflection surface. This idea is embodied in the exploding-reflector concept (Claerbout, 1985). The location, $\Gamma$, is where this normally projecting ray intersects the recording surface. In carrying out the migration calculation of Equation (1), the main contributions to an imaged point on the reflector come from receivers surrounding $\Gamma$. Diffraction theory explains that the phase is stationary at $\Gamma$ and slowly varying in the region surrounding $\Gamma$, allowing coherent summation of wave energy.

The array resolution in the subsurface depends on the array size. A single receiver has a horizontal resolution distance that is defined by the Fresnel zone radius $\sqrt{z \lambda / 2}$, where $z$ is the depth and $\lambda$ is the in situ wavelength. Welch and others (1998) point out that migration using data over the complete surface gives a horizontal resolution distance of $\lambda / 2$, which is approximately $2 \mathrm{~m}$ at $35 \mathrm{MHz}$. If data over the entire bounding surface are not available, or not used, the resolution distance becomes larger. Migration resolution distance is related to the concept of beamwidth from an array of sensors. Figure 4 a shows the normal frequency-domain beam responses $(\mathrm{Ca}-$ pon and others, 1969) for linear arrays of lengths 20, 40 and $80 \mathrm{~m}$. The sensors are spaced at $2 \mathrm{~m}$ intervals. The target is a point reflector $100 \mathrm{~m}$ directly below the center of the array. The $6 \mathrm{~dB}$ beamwidth decreases with array length, giving resolution distances of $9.2,5.0$ and $2.6 \mathrm{~m}$, respectively. This is equivalent to $5.3^{\circ}, 2.9^{\circ}$ and $1.5^{\circ}$ in angular resolution. Since the array sizes are of the order of the depth, the far-field approximation to the beam pattern may not be valid (Stutzman and Thiele, 1981), so a numerical calculation was done for the linear-array response. Figure $4 \mathrm{~b}$ shows the result of applying Equation (1) to the three linear arrays with isotropic sensor elements. The data use a $35 \mathrm{MHz}$ short-pulse wavelet. The migration beamwidth is very similar to the frequency-domain beamwidth shown in Figure 4a. Extending these results to migration with rectangular $60 \mathrm{~m}$ by $40 \mathrm{~m}$ arrays gives approximately $4 \mathrm{~m}$ by $6 \mathrm{~m}$ horizontal resolutions for reflectors buried at $100 \mathrm{~m}$ depth.

Alternative migration methods, such as frequency-wavenumber (Stolt, 1978; Welch and others, 1998) and finite difference (Claerbout, 1976), require a spatial data sampling interval less than the Nyquist interval for the largest wavenumber of interest. This roughly corresponds to one-quarter of the wavelength of the GPR center frequency. In contrast, time-domain Kirchhoff migration tolerates a spatial sample interval larger than one wavelength (about $3.4 \mathrm{~m}$ in ice at $50 \mathrm{MHz}$ ). This comparatively large sample interval is vital to keeping data-collection and -storage costs reasonable. The low spatial sample densities are also less computationally demanding, making the full 3-D waveform migration practical. 